\title{
The thymic flap for bronchial stump reinforcement following lobectomy
}

\author{
MA Wilson ${ }^{1 *}$, ME O'Donnell ${ }^{2}$, SD Cassivi ${ }^{3}$, C Seder $^{3}$ \\ From International Conference for Healthcare and Medical Students (ICHAMS) 2013 \\ Dublin, Ireland. 11-12 October 2013
}

\section{Background}

Reinforcement of the bronchial stump following upper lobectomy has been reported to decrease the prevalence of bronchopleural fistula [1]. A parietal pleural flap remains the mainstay of surgical support for such cases.

\section{Methods}

We present the successful use of the right inferior pole of the thymus for bronchial coverage following upper lobectomy due to extensive pleural adhesions precluding conventional flap coverage.

\section{Results}

A sixty-one year old male presented with a one-day history of severe left chest pain and a five-week history of a nonproductive cough. He had a history of multiple bilateral rib fractures following a motor vehicle accident. He was an exsmoker with no previous asbestos exposure. His respiratory rate was $22 /$ minute with room air oxygen saturation of $95 \%$. He had absent left basal breath sounds. Blood tests were normal. An erect chest $\mathrm{x}$-ray revealed a left sided pleural effusion and a $2.6 \mathrm{~cm}$ right upper lobe mass, confirmed with CT imaging..Although bronchoscopy and thoracocentesis were negative for malignancy, transbronchial endoscopic ultrasound needle aspiration of station $4 \mathrm{R}$ lymph nodes reported non-small cell lung carcinoma (T1B,M0,N2). He responded to neoadjunctive chemoradiotherapy. Follow-up PET/CT imaging showed a reduction in the apical mass to $2.2 \mathrm{~cm}$. Right upper lobectomy was performed via a 5 th ribspace posterolateral thoracotomy where a solitary malignant intrapulmonary peribronchial lymph was identified. Due to extensive pleural adhesions from previous rib fractures, the right inferior tip of the thymus was mobilized from the pericardium and retrosternal attachments and used to secure

\footnotetext{
${ }^{1}$ Royal College of Surgeons in Ireland, 123 St. Stephen's Green, Dublin 2. Ireland

Full list of author information is available at the end of the article
}

the bronchial stump. The patient remains well following an uneventful recovery. Post-lobectomy bronchopleural fistula remains a rare and serious complication with an incidence rate between $0.5 \%-0.99 \%$ [2]. Persistent empyemas necessitating open drainage and prolonged hospitalization contribute to a high mortality rate ranging from $25 \%-67 \%$ [2]. A reduction in complications had been reported with the incorporation of pleural,diaphragmatic, intercostal and azygous vein bronchial stump reinforcements [1]. In our case, the thymic flap was mobilized due to inability to successfully dissect the parietal pleura. Infante et al (2004) evaluated the protection of right pneumonectomy bronchial sutures with a pedicled thymus flap where $82 \%$ $(27 / 33)$ of cases had a satisfactory thymic inferior pole length [3].

\section{Conclusions}

The thymic flap appears to be a valid conduit for reinforcement of the bronchial stump particularly in patients with extensive pleural adhesions limiting mobilization of the other traditional flaps.

\footnotetext{
Authors' details

${ }^{1}$ Royal College of Surgeons in Ireland, 123 St. Stephen's Green, Dublin 2.

Ireland. 'Division of Vascular and Endovascular Surgery, Mayo Clinic, Arizona, USA. ${ }^{3}$ Division of Thoracic Surgery, Mayo Clinic, Rochester, USA.
}

Published: 14 January 2015

\section{References}

1. Al-Mufarrej F, et al: Bronchial stump reinforcement with an azygous vein flap. J Cardiothorac Surg 2009, 4:22.

2. Mohamed Sadok, et al: Conservative management of postoperative bronchopleural fistulas. J Thorac Cardiovasc Surg, In Print.

3. Infante MV, et al: Protection of Right Pneumonectomy Bronchial Sutures With a Pedicled Thymus Flap. Ann Thorac Surg 2004, 77(1):351-3.

doi:10.1186/1753-6561-9-S1-A44

Cite this article as: Wilson et al:: The thymic flap for bronchial stump reinforcement following lobectomy. BMC Proceedings 2015 9(Suppl 1): A44.

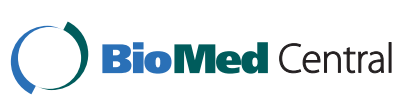

(c) 2015 Wilson et al; licensee BioMed Central Ltd. This is an Open Access article distributed under the terms of the Creative Commons Attribution License (http://creativecommons.org/licenses/by/4.0), which permits unrestricted use, distribution, and reproduction in any medium, provided the original work is properly cited. The Creative Commons Public Domain Dedication waiver (http:// creativecommons.org/publicdomain/zero/1.0/) applies to the data made available in this article, unless otherwise stated. 